\title{
Política social, desigualdad y pobreza, el caso de México
}

\section{Social policy, inequality and poverty, the case of Mexico}

\section{Gutiérrez, Flores Luis e Ignacio Llamas Huitrón (20i6),} Política social, DESIGUALDAD Y POBREZA, EL CASO DE MÉXICO, Fontamara, Ciudad de MÉxico, MÉxico, 240 PP., ISBN: 978-607-

$$
\text { 7362-87-6. }
$$

México un país atrapado en el mal desarrollo, con una población caracterizada por sus carencias, víctima de un sistema educativo público de pésima calidad que es incapaz de ofrecer los elementos culturales y tecnológicos necesarios para sobreponerse a la miseria. Clasificado sin discusión como un país pobre y desigual, en el que la regla es el estancamiento económico, a el que se suma la inseguridad, la violencia criminal, la informalidad y el deterioro ecológico.

El panorama es desolador, a lo anterior se agrega una corrupción generalizada en todos los ámbitos de la sociedad, particularmente grave en el sector público. Todo el que llega a un puesto público, pareciera programado para abusar de su cargo en beneficio privado, la transparencia y el seguimiento a las normas son mero discurso. La realidad el desvío de recursos, el nepotismo, el compadrazgo y la virtual intolerancia del mérito como forma de ascenso social. Esto sin olvidar que muchos y muchas sin pertenecer al sector público de manera formal, viven de él por medio de la creación de grupos de presión, los cuales puntualmente reciben una compensación por su contribución al desorden y caos.

Aunque este escenario es trágico, existen algunas acciones que se llevan a cabo para revertirlo, no todos los actores de la sociedad mexicana aceptan pasivamente este contexto, diariamente buscan competir (otros subsistir), se niegan a que todo siga igual y a su manera contribuyen a cambiarlo en beneficio de una amplia mayoría. Afortunadamente, existen personas en el gobierno, en la empresa privada, en las organizaciones de la sociedad civil y por supuesto en las universidades que encabezan un grupo que se opone a la miseria económica, social y espiritual.

El reclamo es que el Estado retome la conducción del progreso, que lo haga de una forma en la que los beneficiados sean los más y no los menos, que asuma la corrección de las desigualdades en la escala regional 
y personal. Que reconozca e integre a todas las fuerzas creativas y productivas para hacer de México un país material y espiritualmente sano.

Precisamente, en esta dirección, en 2012, un grupo de profesores e investigadores decidió establecer una Red de Análisis y Evaluación de las Políticas Económicas y Sociales, en la que participarían la Universidad Autónoma de Coahuila, particularmente el Centro de Investigaciones Socioeconómicas como institución responsable, la Universidad Autónoma Metropolitana campus Iztapalapa, la Universidad Nacional Autónoma de México, el Centro de Investigación en Alimentación y Desarrollo, Sam Houston University y la Universidad Autónoma de Ciudad Juárez. La red recibió apoyo económico del Programa de Mejoramiento del Profesorado de la Secretaría de Educación Pública, lo que permitió financiar a los participantes, tanto profesores como estudiantes.

La meta principal de la red: el diagnóstico de las carencias, necesidades y limitaciones de las políticas enfocadas a la mejora de las condiciones de producción, distribución, consumo y bienestar de los mexicanos en la escala nacional y regional, de cara a la integración económica y tecnológica que se vive en México. Sin dejar de lado la presentación de estrategias y políticas eficaces, eficientes y efectivas bajo la regla de la mayoría.

El libro Politica social, desigualdad y pobreza, el caso de México, es la evidencia de lo que se ha indicado, se compone de ochos capítulos en los que participan profesores de larga trayectoria y reconocimiento, pero también estudiantes en proceso de formación y jóvenes investigadores representantes de un México que no desea condenarse al rezago, conscientes de la importancia que tiene el esfuerzo intelectual y el uso de criterios técnicos para criticar y establecer mecanismos para un país mejor.

El primer capítulo fue realizado por Alessandro Bonano, lo tituló: "El contexto internacional para el análisis y la evaluación de las políticas sociales en México", en éste, el autor destaca la presencia de la globalización neoliberal, concepto muy usado por el mundo académico heterodoxo para identificar las contradicciones (pobreza y desigualdad) del sistema capitalista internacional. Señala que México es uno de los países donde más adelantada se encuentra la revolución neoliberal y con ello sus funestas consecuencias. De acuerdo con el autor, la tarea básica de la agenda neoliberal es minimizar la intervención estatal y fortalecer el individualismo. Agrega que, de continuar su profundización, se seguirán erosionando las políticas sociales, lo que se suma a los bajos salarios y reducido poder de negociación obrera.

La concentración de la riqueza es la norma, y para los defensores del neoliberalismo, dice Bonanno, la solución consiste en profundizar las reformas. Su capítulo invita a reflexionar en torno a la crisis de legitimación del Estado, caracterizada por una contradicción: si interviene se 
concentra en las élites que dominan el mundo financiero y productivo y si no lo hace genera estancamiento. Termina preguntándose: ¡cómo enfrentar el reto del desarrollo económico? Si por un lado el Estado tiene fallas y el mercado también, cuál es el mejor camino por seguir. Al final expone que es necesario reflexionar en torno a nuevas teorías para entender y propiciar un mejor desarrollo.

En el segundo capítulo, denominado: "Tendencia de las políticas sociales en México y el enfoque de género", Lourdes Ampudia Rueda contribuye con una breve historia de la política social en México para analizar su enfoque de género. Algo que para la autora es fundamental, ya que recuerda que las mujeres tienen un rol productivo y familiar. Estudia la forma en la que el gobierno federal ha atendido las problemáticas de las mujeres, particularmente desde el 2000, con la creación del Instituto Nacional de las Mujeres. Encuentra que la política social ha fallado al continuar centralizada y dejar de lado la visión de género. Su capítulo es de utilidad para aquellos estudiantes que se encuentran interesados en los estudios de género y la política social. Claramente atiende al principio de evaluar las políticas sociales en México.

Por otra parte, Luis Gutiérrez Flores, Mónica Rodríguez y Luis Huesca Reynoso, en el tercer capítulo: "Un diagnóstico reciente acerca de la pobreza y la desigualdad en las regiones de México", se concentran en comparar la pobreza y la desigualdad en las regiones de México para los años 2000 y 2010. Calculan diversos indicadores como conteo de pobreza, brecha de pobreza, índice de Atkinson, índice de Gini, curva de Lorenz y funciones de densidad de Kernel. El principal hallazgo es que las disminuciones de pobreza no se correspondieron con reducciones en la desigualdad. El capítulo es recomendable para quienes desean adentrarse al análisis de pobreza con datos provenientes de las Encuestas Nacionales de Ingreso-Gasto de los Hogares (ENIGH). De hecho, un elemento unificador de los trabajos presentados en este libro es precisamente el uso de dicha fuente de información (con todo y los problemas de representatividad que tiene cuando se desea trabajar en una escala diferente a la nacional).

La primera mitad del libro cierra con el capítulo: "El programa Oportunidades: impacto y focalización al finalizar la primera década del siglo XXI", elaborado por Joaquín Bracamontes y Mario Camberos Castro. En este trabajo se explica a detalle el programa y se concluye que tiene problemas de focalización, o bien excluye pobres (error tipo I) o bien incluye a personas no pobres (error tipo II). El trabajo estima la pobreza para los años 2006, 2008 y 2010, usando micro-simulación estática y el método de líneas de pobreza, así como el índice FGT. Encuentran que 
Oportunidades no ayuda a reducir la pobreza, por lo tanto, debe replantearse su diseńo y dinámica de operación.

La evaluación de los programas sociales continúa en el capítulo cinco: "El programa de apoyo alimentario: una alternativa para los excluidos de oportunidades", escrito por Luis Huesca Reynoso y Mario Camberos Castro. Los autores presentan el programa, y aproximan la población potencial y la cantidad mínima de recursos por medio de la ENIGH 2010. Técnicamente usan las curvas de pobreza para identificar la cobertura e impacto del programa. Hallan que el programa cubre solamente 677,124 hogares, cuando debería atender a 3,721,473 hogares. Su conclusión es que el programa de apoyo alimentario tiene problemas de focalización y cobertura. Al final proponen realizar una encuesta para conocer el impacto en alimentación y educación de los niños menores a nueve años.

"Desigualdad salarial como efecto de la apertura comercial en el mercado laboral de Zacatecas y Aguascalientes: un estudio comparativo" es el capítulo seis, realizado por Albany Aguilera, David Castro y Reyna Rodríguez. El trabajo analiza el efecto de la apertura comercial sobre los salarios y el nivel de desigualdad salarial en el interior de la zona metropolitana de Zacatecas y de Aguascalientes entre 1992, 2001 y 2010, también realiza una comparación entre ambas entidades. Dos son los principales resultados: 1) los salarios son más elevados para los grupos con mayor nivel de educación y 2) la desigualdad en las dos ciudades se ha mantenido constante. Adicional a esto se estudia la forma en la que la edad, género y las actividades económicas inciden sobre las inequidades salariales.

El séptimo capítulo se denomina: "Segregación ocupacional por género en la industria metalmecánica en México 2000-2010”, escrito por Juana Delgadillo, Gilberto Aboites y Nora Garro. Su objetivo es tratar de entender las razones de la segregación ocupacional de la industria de Aguascalientes, Baja California, Chihuahua, Coahuila, Estado de México, Guanajuato, Morelos, Nuevo León, Puebla, Querétaro, San Luis Potosí y Sonora. En cuanto al método calcularon cuatro índices: 1) representación, 2) disimilitud, 3) segregación y 4) participación. Encontraron que es significativa la participación de mujeres en las ocupaciones consideradas de liderazgo, tales como las de director y gerente en producción manufacturera, así como coordinador y jefe de área en producción manufacturera. A pesar de esto, el grado de participación femenina en la rama metalmecánica del país aún está por debajo de la media nacional.

El libro lo cierran Ignacio Llamas y José Jimenez, con su capítulo: "El hogar rural receptor de remesas. El caso de México, 2006 y 2010”, el cual explora un tema largamente estudiado en las ciencias sociales: la migración y las remesas recibidas por un hogar; no obstante, innovan al centrarse en 
el espacio rural y usar las ENIGH de 2006 y 2010 junto a un modelo logit binominal para determinar la probabilidad de que un hogar reciba remesas, en función del estado civil, sexo y escolaridad del jefe del hogar, tamaño del hogar, proporción de hombres en el hogar, clima educativo del hogar, proporción de los miembros del hogar que asisten a la escuela, tasa de dependencia y una variable regional. El estudio concluye que todas las variables incluidas eran relevantes, lo que variaba era su orden de importancia.

Como todo libro coordinado o compilado, se sugiere revisarlo en función de los intereses particulares que se tengan, tal y como se hace con una revista de investigación científica. Con esta reseña lo que se ha pretendido es presentarlo a la comunidad académica e intelectual y revelar que representa un esfuerzo importante por aportar al debate respecto a la forma en la que han funcionado los programas públicos que atienden problemáticas sociales y económicas. Quien lea el libro seguramente podrá tener más elementos para construir una mejor sociedad, sea en México o bien en América Latina, esto por la vía de una mejor ciencia y técnica.

ISAAC SÁNCHEZ-JUÁREZ isaac.sanchez@uacj.mx Universidad Autónoma de Ciudad Juárez

Recibido: 19 de abril de 2018. Reenviado: 20 de abril de 2018. Aceptado: 23 de abril de 2018.

Isaac Sánchez-Juárez. Doctor en Estudios Regionales por El Colegio de la Frontera Norte (El Colef). Actualmente es profesor-investigador de la Universidad Autónoma de Ciudad Juárez. Es miembro del Sistema Nacional de Investigadores, nivel I. Sus líneas de investigación actuales son Crecimiento económico en México, macroeconomía aplicada y problemas estructurales de México. Entre sus últimas publicaciones destacan: "Gasto público, índice de competitividad y política social en México”, Problemas del Desarrollo 49 (192), Universidad Nacional Autónoma de México, Ciudad de México, México, pp. 109-138 (2018); "Modelo IS-LM: Simulación matemática y aplicación en México", Ciencias Económicas 14 (02), Universidad Nacional del Litoral, Santa Fe, Argentina, pp. 9-27 (2017) y "El reto del crecimiento económico en México. Industrias manufactureras y política industrial", Revista Finanzas y Política Económica, 8 (2), Universidad Católica de Colombia, Bogotá, Colombia, pp. 271-299 (2016). 